\title{
Lechiguana em bovinos: aspectos patogênicos
}

\author{
Lechiguana in cattle: pathogenic aspects
}

\section{Silvia Ladeira' ${ }^{\text {Franklin Riet-Correa }}{ }^{\text {II }}$ Josiane Bonel-Raposo $^{\text {III }}$ Cléia Cardoso Pacheco ${ }^{\text {IV }}$ Eduardo Juan Gimenov Enrique Leo Portianskyv}

\section{RESUMO}

Dois bovinos foram infectados com larvas de Dermatobia hominis na região escapular esquerda, e o local de infecção de um dos bovinos foi inoculado com Mannheimia granulomatis. Aos sete, 14, 21 e 28 dias, foram feitas biópsias cirúrgicas dos locais de inoculação das larvas para posterior estudo histológico, imuno-histoquímico e avaliação por microscopia eletrônica de transmissão. No bovino infectado somente com as larvas, as lesões histológicas se caracterizaram por dermatite eosinofílica, infiltrado de células mononucleares e proliferação de tecido conjuntivo. A inoculação simultânea de Dermatobia hominis e Mannheimia granulomatis provocou adicionalmente linfangite e microabscessos eosinofílicos, similares aos observados em casos espontâneos da enfermidade. $\mathrm{Na}$ amostra coletada aos 28 dias após a infecção bacteriana, foi observada, tanto na imuno-histoquímica, como por meio da microscopia eletrônica, a presença de corpos bacterianos aparentemente intactos no interior de fagossomas macrofágicos, sugerindo que a bactéria permanece dentro dos macrófagos até que algum fator desconhecido desencadeie o desenvolvimento da enfermidade. A Mannheimia granulomatis foi isolada de larvas coletadas aos 42 dias após a inoculação, demonstrando que a bactéria pode sobreviver por algum tempo na larva de Dermatobia hominis. Os dados do trabalho indicam que as larvas de Dermatobia hominis podem atuar como um fator contribuinte para o desenvolvimento da paniculite fibrogranulomatosa proliferativa.

Palavras-chave: Mannheimia granulomatis, Dermatobia hominis, paniculite fibrogranulomatosa proliferativa, lechiguana, bovinos.

\begin{abstract}
Two cattle were infected at the left scapula with larvae of the Dermatobia hominis, while one of them was infected with the Mannheimia granulomatis. Biopsies of the lesions were taken at the 7, 14, 21 and 28 days p.i. for subsequent histopatological, immunohistochemical and electron microscopical studies. In the only animal infected with larvae, eosinophilic dermatitis, infiltration of mononuclear cells and proliferation of connective tissue characterized the histological lesions. The simultaneous inoculation of Dermatobia hominis and Mannheimia granulomatis caused, besides the characteristic lesions of the parasitosis, linfangitis and eosinophilic microabscesses, similar changes to those observed in spontaneous cases of the disease. In the samples taken after 28 days of the bacterial infection it was observed, in both immunohistochemestry and by electronic microscopy the presence of apparently intact bacterial bodies inside macrophages fagosomes, suggesting that the bacteria is inside the macrophages until some unknown factors trigger the development of the illness. Mannheimia granulomatis was isolated from larvae gathered 42 days after inoculation demonstrating that the bacteria can survive inside the larva Dermatobia hominis. Data from the study indicate that the larvae of Dermatobia hominis may act as a contributing factor to the development of proliferative fibrogranulomatous panniculitis.
\end{abstract}

Key words: Mannheimia granulomatis, Dermatobia hominis, proliferating fibrogranulomatous panniculitis, lechiguana, bovine.

'Laboratório Regional de Diagnóstico, Faculdade de Veterinária, Universidade Federal de Pelotas (UFPel), 96010-900, Pelotas, RS, Brasil. E-mail: sladeira@via-rs.net. Autor para correspondência.



IIIDepartamento de Patologia, Faculdade de Veterinária, UFPel, Pelotas, RS, Brasil.

IV Prefeitura Municipal de Pelotas, Pelotas, RS, Brasil.

vFaculdade de Ciências Veterinárias, Universidade Nacional de La Plata (UNLP), La Plata, Argentina. 


\section{INTRODUÇÃO}

Lechiguana é uma enfermidade de bovinos definida como um paniculite fibrogranulomatosa proliferativa caracterizada por tumoração subcutânea de crescimento rápido, com marcada proliferação de tecido fibroso, que, quando não tratada, ocasiona a morte do animal em um período de três a oito meses. Afeta animais de todas as idades, raças e sexo (RIETCORREA et al., 1992).

A enfermidade foi observada pela primeira vez em uma área de serra de mata nativa de aproximadamente 500.000 hectares, próxima ao Município de Pelotas, Rio Grande do Sul (RIETCORREA et al., 1992). Posteriormente, foi descrito um caso proveniente do Município de Cachoeira do Sul, localizado em outra região do Rio Grande do Sul (PEREIRA et al., 2000). Também foram descritos outros casos provenientes dos Estados de Santa Catarina, Paraná, São Paulo (BIRGEL JR et al., 1999) e Minas Gerais (VARASCHIN \& SILVA, 1998). Mais recentemente, a bactéria foi isolada na Austrália (BLACKALL et al., 2002) e na Dinamarca (ANGEN et al., 2002).

Todos os casos de lechiguana foram observados em animais provenientes de áreas geograficamente localizadas onde o parasitismo por Dermatobia hominis é frequente (RIET-CORREA et al., 1992). Clinicamente, a lesão da enfermidade nos animais se caracteriza por desenvolvimento de grandes massas tumorais de consistência dura localizadas, geralmente, na região escapular, podendo também ocorrer em outros locais como região glútea, dorso lombar, abdominal e peitoral (RIET-CORREA et al., 1992; LADEIRA et al., 1996; PEREIRA, 1997).

Uma característica marcante da enfermidade é a rápida proliferação de tecido fibroso durante o desenvolvimento desta, assim como a rápida regressão da lesão depois do tratamento com antibióticos. São desconhecidos os mecanismos patogênicos que determinam esse rápido crescimento e a reabsorção do tecido fibroso, assim como outros aspectos da patogenia da enfermidade (RIET-CORREA et al., 1992).

A evolução clínica é rápida e, na maioria dos casos descritos, varia de dois a 12 meses. As massas subcutâneas desenvolvem dimensões máximas de 45 a $50 \mathrm{~cm}$ de diâmetro, sobressaindo de 5 a $25 \mathrm{~cm}$ sobre a superfície da pele. A pele que cobre a lesão se apresenta espessa, escamosa, frequentemente alopécica e ulcerada, com nódulos de Dermatobia hominis, e há também aumento de tamanho dos linfonodos regionais. Os bovinos afetados têm emaciação progressiva e morte se a enfermidade não é tratada (RIET-CORREA et al., 1992).
A etiologia da enfermidade não tem sido totalmente estabelecida, mas alguns estudos sugerem uma associação entre o parasitismo da Dermatobia hominis e a presença da bactéria Gram negativa, Mannheimia granulomatis. Essa bactéria foi isolada em 30 de 40 casos da enfermidade e marcada por meio do método imuno-histoquímico nos 10 casos restantes (RIET-CORREA et al., 2000).

O objetivo deste trabalho foi complementar o estudo da patogenia de lechiguana, utilizando as técnicas de microscopia ótica e eletrônica de transmissão (MET) e imuno-histoquímica (IHQ) em estudo evolutivo da doença, reproduzida experimentalmente.

\section{MATERIAL E MÉTODOS}

Para o estudo, foram utilizados dois bovinos (Bovino 1 e Bovino 2) da cruza entre as raças Charolês e Hereford, com dois anos de idade e peso aproximado de $300 \mathrm{~kg}$. Foram coletadas 533 larvas de terceiro estágio (L3) de Dermatobia hominis de bovinos espontaneamente infestados em campos próximos ao Município de Pelotas, Rio Grande do Sul.

As larvas foram selecionadas e colocadas em vidros com serragem lavada, esterilizada e umedecida. As larvas foram mantidas a $27^{\circ} \mathrm{C}$, em estufa de germinação tipo BOD, com fotoperíodo e umidade relativa de 70 a $80 \%$, durante aproximadamente 30 dias, até alcançar o estágio de pupa. Logo depois da eclosão das moscas, foram realizados a sexagem, o acasalamento e a produção de ovos e de larvas infectantes (L1).

Amostras de Mannheimia granulomatis isoladas das lesões de um caso espontâneo de lechiguana foram semeadas em agar sangue ovino a $5 \%$ e incubadas a $37^{\circ} \mathrm{C}$, durante 24 horas. O cultivo foi suspenso em uma solução salina a $0,85 \%$, com um grau de turbidez correspondente ao tubo 3 da escala de McFarland $\left(\sim 2,3 \times 10^{5}\right.$ unidades formadoras de colônias por mililitro- $\left.\mathrm{UFC} \mathrm{ml}^{-1}\right)$.

O Bovino 1 foi infectado com 46 larvas infectantes (L1) de Dermatobia hominis produzidas no laboratório. As L1 foram inoculadas na região escapular mediante a ajuda de um pincel de ponta fina (RIBEIRO \& DE OLIVEIRA, 1983). O Bovino 2 foi infectado com 89 larvas infectantes (L1) de Dermatobia hominis. Antes da inoculação das L1 no Bovino 2, os sítios de inoculação foram pincelados com uma suspensão de Mannheimia granulomatis. A infecção com a suspensão bacteriana foi repetida semanalmente durante quatro semanas. A diferença entre o número de larvas inoculadas em Bovino $1 \mathrm{e}$ Bovino 2 se deve ao número de larvas que eclodiram a 
cada dia. Dessa maneira, se manteve um controle exato da evolução das lesões e do crescimento de cada larva. Para determinar a evolução das lesões, foram realizadas biópsias por incisão cirúrgica em ambos os bovinos, sendo retiradas as larvas sempre acompanhadas da lesão circundante e da pele. Essas biópsias foram realizadas aos sete, 14 e 21 dias pósinfecção (p.i.). No Bovino 2, foi realizada uma biópsia adicional aos 28 dias p.i. O material extraído foi fixado em formol $10 \%$ tamponado, durante 24 horas, embebido em parafina, cortado em secções de $5 \mu \mathrm{m}$ e corados com hematoxilina e eosina (HE) (LUNA, 1968).

O material extraído do Bovino 2, aos 28 dias p.i., foi submetido à IHQ. Os blocos de parafina positivos na IHQ, para Mannheimia granulomatis, foram utilizados para confirmar a presença desta mediante estudos de MET.

Aos 42 dias p.i., foram coletadas quatro larvas de terceiro estágio (L3) de Dermatobia hominis provenientes da infecção experimental do Bovino 2. Duas larvas foram semeadas em agar sangue ovino a $5 \%$, e as outras duas foram colocadas em vidros com serragem previamente lavada, esterilizada e umedecida, e mantidas a $27^{\circ} \mathrm{C}$, em estufa de germinação tipo BOD, com fotoperíodo e umidade relativa de 70 a $80 \%$, durante aproximadamente 30 dias, até alcançar o estágio de pupa. As pupas foram semeadas em agar sangue ovino a $5 \%$, para detectar a presença de Mannheimia granulomatis.

Para a avaliação por IHQ, foi utilizado somente o material extraído do Bovino 2 aos 28 dias p.i. e soro policlonal purificado anti-Mannheimia granulomatis produzido em coelho e diluído a 1:4000 (LADEIRA, 2005). O método utilizado foi o complexo estreptavidina-biotina-peroxidase (KIT Complexo ABC - K0690, Dako Corporation, Carpinteria, Califórnia, EUA). Resumidamente, a técnica consistiu da incubação das seções de $3 \mu \mathrm{m}$ cortadas a partir de blocos de parafina com o material coletado das biópsias, colocadas em lâminas de vidro silanizadas, após adicionado o anticorpo primário (específico), seguido da incubação com anticorpo biotinilado. Finalmente foi realizada a incubação com uma solução de estreptavidina marcada com peroxidase. Antes da incubação com o soro anti-Mannheimia granulomatis, os cortes foram tratados com "bloqueador universal" (Universal Blocking Reagent, Biogenex, USA), para bloquear reações inespecíficas. A revelação foi realizada com 3', 3' - diaminobenzidina (DAB) a $0,02 \%$ e $\mathrm{H}_{2} \mathrm{O}_{2}$ a $0,05 \%$.

Para o estudo por microscopia eletrônica, os blocos de parafina cujos tecidos foram positivos na IHQ para Mannheimia granulomatis foram desparafinizados, e o material foi refixado em glutaraldeído a $2 \%$, em uma solução $0,1 \mathrm{M}$ de cacodilato de sódio, $\mathrm{pH} 7,4$. Posteriormente, foi pós-fixado em uma solução a $1 \%$ de tetróxido de ósmio, em uma solução $0,1 \mathrm{M}$ de cacodilato de sódio e embebido em Epon812. Cortes semifinos foram corados com azul de toluidina e a partir destes foram selecionados e realizados cortes ultrafinos que foram corados com citrato de chumbo e acetato de uranil e observados ao MET (Zeiss Electrón Microscope EM109).

\section{RESULTADOS}

$\mathrm{Na}$ avaliação histológica das amostras obtidas do Bovino 1 aos sete dias p.i., foi observado que a larva apresentava-se rodeada por exsudato contendo neutrófilos, eosinófilos e fibrina. Na derme que circundava esse exsudato, foram observados edema, infiltrado de células mononucleares, eosinófilos e fibroblastos, com formação de tecido conjuntivo jovem. Na periferia da lesão, foi observado infiltrado perivascular de células mononucleares e eosinófilos. Aos 14 e 21 dias p.i., as lesões foram similares às lesões encontradas no dia 7 p.i. e adicionalmente foram observadas hiperplasia da epiderme e maior intensidade de infiltrado inflamatório mononuclear, com presença de colágeno, fibroblastos e macrófagos.

Nas amostras do Bovino 2, obtidas aos sete, 14 e 21 dias p.i., as alterações eram similares as do Bovino 1. Não obstante, as amostras do dia 7 p.i., no exsudato que circundava, a larva tinha material eosinofílico granular, sugerindo a formação de Splendore-Hoeppli (McGAVIN \& ZACHARY, 2007). Além disso, foram observadas áreas focais na derme com evidente proliferação de fibroblastos. Aos $14 \mathrm{e}$ aos 21 dias p.i., foram observados, além das lesões anteriormente descritas, microabscessos constituídos principalmente por eosinófilos. Aos 21 dias p.i., também foram observados vasos linfáticos dilatados, contendo eosinófilos e fibroplasia mais acentuada que no do Bovino 1.

Aos 28 dias p.i., as amostras do Bovino 2 evidenciaram grande quantidade de vasos neoformados, espessamento da parede vascular, numerosas fibras de tecido conjuntivo e fibroblastos na região próxima à localização da larva.

A Mannheimia granulomatis foi isolada da hemolinfa das 2 larvas coletadas do Bovino 2 aos 42 dias p.i., não sendo isolada das pupas. Na técnica de imuno-histoquímica, houve marcação positiva para Mannheimia granulomatis no exsudato inflamatório, ao redor e no interior do parasito (Figura 1A) e em macrófagos (Figura 1B). A MET confirmou a presença da bactéria no exsudato inflamatório, ao redor da larva, 




conforme marcação observada por meio da técnica de IHQ. Os corpos bacterianos foram vistos fagocitados por macrófagos (Figura 1C), permanecendo aparentemente intactos no interior de fagossomas ou livres no tecido (Figura 1D).

\section{DISCUSSÃO}

Em estudos prévios (RIET-CORREA et al., 1992; LADEIRA, 1996; PEREIRA, 1997; PEREIRA et al., 2000), foi demonstrado que lechiguana é uma enfermidade causada pela bactéria Pasteurella granulomatis, posteriormente denominada Mannheimia granulomatis. A enfermidade se caracteriza morfologicamente por paniculite fibrogranulomatosa proliferativa com linfangite e abscessos eosinofílicos. Os autores também sugerem que a causa da enfermidade pode ser uma associação da bactéria com a larva da mosca Dermatobia hominis.
As lesões encontradas (nos dois bovinos deste estudo), assim como as características histológicas observadas, foram comparáveis com as descrições de SANAVRIA et al. (1987) e PEREIRA et al. (2000). Este último autor descreve lesões contendo microabscessos e linfangite eosinofílica em um animal inoculado experimentalmente com Dermatobia hominis e Mannheimia granulomatis. A linfangite eosinofilica, com ruptura da parede de vasos sanguíneos e formação de microabscessos eosinofílicos, também são descritas como lesões primárias de lechiguana (RIET-CORREA et al., 1992). A observação dessas lesões em três estudos realizados sobre biópsias indica que a infecção bacteriana é a responsável pela presença da linfangite e de abscessos eosinofílicos. A marcada proliferação de tecido fibroso, observada nos casos espontâneos da enfermidade (RIET-CORREA et al., 1992), não foi reproduzida no presente trabalho. 
Na biópsia realizada aos 28 dias p.i. de Dermatobia hominis, foram observadas bactérias no interior dos macrófagos, tanto nos estudos com MET, como nos estudos de IHQ. ANDRADE (1999) relata, por meio da reação IHQ, a marcação da Mannheimia granulomatis no interior ou ao redor dos microabscessos ou da linfangite eosinofílica, ou próxima ao acúmulo de células inflamatórias nos casos espontâneos da enfermidade. A presença dos corpos bacterianos aparentemente intactos no interior dos fagossomas macrofágicos sugere que essas bactérias tenham um mecanismo que evita que a vesícula endocítica se junte com o lisossoma, impedindo, dessa forma, a exposição às enzimas lisossomais, semelhante ao que ocorre quando os macrófagos fagocitam Mycobacterium tuberculosis, Toxoplasma gondii, Encephalitozoon cuniculi e algumas Chlamydiae (FRIEDMAN et al., 1980).

Nos três casos em que a enfermidade foi reproduzida experimentalmente, a lesão foi observada 34 dias após a inoculação em dois casos (RIETCORREA et al., 1992; LADEIRA et al., 1996) e 90 dias em um caso (PEREIRA et al., 2000). Com esses dados, é possível especular que a bactéria permanece nos macrófagos do hospedeiro até que, por algum fator patogênico desconhecido, desencadeie a enfermidade ou se produza a destruição desta (JANEWAY et al., 2002). O isolamento de Mannheimia granulomatis da hemolinfa das larvas coletadas aos 42 dias depois da inoculação, assim como a observação da bactéria no interior e no exsudato inflamatório ao redor da larva mediante a técnica de IHQ, demonstrou que Mannheimia granulomatis é capaz de sobreviver no interior das larvas. Essa possibilidade foi evidenciada por LADEIRA et al. (1996), os quais isolaram Mannheimia granulomatis de larvas coletadas de um animal proveniente de uma propriedade onde não haviam ocorrido casos de lechiguana.

\section{CONCLUSÕES}

Por meio das técnicas de IHQ e MET, foi possível determinar a presença de Mannheimia granulomatis no exsudato inflamatório, ao redor da Dermatobia hominis e no interior deste. Corpos bacterianos foram também observados livres na lesão ou fagocitados por macrófagos. Mannheimia granulomatis é capaz de sobreviver no interior das larvas de Dermatobia hominis. A reação granulomatosa produzida pela Dermatobia hominis pode ser a lesão inicial de lechiguana quando a bactéria está presente.

\section{AGRADECIMENTOS}

Este trabalho foi financiado pela Fundação de Amparo à Pesquisa do Estado do Rio Grande do Sul (FAPERGS) (processo n ${ }^{\circ}$ 00/208848.8).

\section{REFERÊNCIAS}

ANDRADE, G.B. Estudo histoquímico, morfométrico e molecular do colágeno na paniculite fibrogranulomatosa proliferativa focal dos bovinos (lechiguana). 1999. $88 \mathrm{f}$. Tese (Doutorado em Patologia Experimental e Comparada) Curso de Pós-graduação em Patologia Experimental e Comparada, Universidade de São Paulo, SP.

ANGEN, O. et al. Phenotypic and genotypic characterization of Mannheimia (Pasteurella) haemolytica-like strains isolated from diseased animals in Denmark. Veterinary Microbiology, v.84, n.1-2, p.103-14, janeiro, 2002. Disponível em: <http:// w w w. s c i e n c e d i r e c t. c o m / science?_ob=ArticleListURL\&_method=list\&_ArticleListID $=$ $1170000282 \&$ \& sort $=$ r\& $\&$ ie w $=$ c \&_a c c t $=$ C 00005 $0221 \&$ \& ersion $=1 \&$ \& ur l Vers i o $n=0 \&$ \& s e rid $=10 \&$ md $5=$ efbbed90a $1 \mathrm{e} 4 \mathrm{f} 3 \overline{4} 1 \mathrm{a} 2 \mathrm{fb} 411932112 \mathrm{a} 58>$. Acesso em: 18 jan. 2010. doi: 10.1016/S0378-1135(01)00439-4.

BIRGEL Jr., E.H. et al. Ocorrência de lechiguana (paniculite fibrogranulomatosa proliferativa) em bovino criado no Estado de São Paulo. Arquivos do Instituto Biológico, v.66, supl., p.130. 1999. In: CONGRESSO BRASILEIRO DE BUIATRIA, 3.; Congresso Paulista de Buiatria, 2.; Curso de Atualização em Clínica Buiátrica, 4. São Paulo, Impresso. ISSN/ISBN: 00203653.

BLACKALL, P.J. et al. Phenotypic characterisation of Australian sheep and cattle isolates of Mannheimia haemolytica, Mannheimia granulomatis and Mannheimia varigena. Australian Veterinary Journal, v.80 n.1-2, p.8791, 2002. Disponível em: <http://dx.doi.org/10.1111/j.17510813.2002.tb12058.x>. Acesso em: 18 jan. 2010. doi: 10.1111/j.1751-0813.2002.tb12058.x.

FRIEDMAN, H. et al. The reticuloendothelial system: a comprehensive treatise. Estados Unidos: Plenum, 1980. $793 \mathrm{p}$.

JANEWAY, C.A. et al. Imunobiologia. O sistema imune na saúde e na doença. 5.ed. Porto Alegre: Artmed, 2002. $767 \mathrm{p}$.

LADEIRA, S.L. et al. Role of Pasteurella granulomatis and Dermatobia hominis in the etiology of lechiguana in cattle. Annals of the New York Academy of Sciences, v.791, p.359-368, 1996. Disponível em: <http://dx.doi.org/10.1111/ j.1749-6632.1996.tb53543.x>. Acesso em: 17 dec. 2006. doi: $10.1111 /$ j.1749-6632.1996.tb53543.x.

LADEIRA, S. Lechiguana en bovinos: aspectos patogénicos en la enfermedad. 2005. 42f. Tese (Doutorado em Ciências Veterinárias) - Curso de Pós-graduação em Ciências Veterinárias, Universidade Nacional de La Plata, La Plata, Argentina.

LUNA, G.L. Manual of histologic stainning methods of the Armed Forces Institut of Pathology. New York, MC Graaw-Hill, 1968. 285p. 
McGAVIN, M.D.; ZACHARY J.F. Pathologic basis of Veterinary diseases. St. Louis, Missouri: Mosby Elsevier, 2007. p. 1476 .

PEREIRA, D.B. Lechiguana: aspectos patogênicos, estudo de portadores de Pasteurella granulomatis e novos casos da doença em bovinos. 1997. 51f. Dissertação (Mestrado em Ciências Veterinárias) - Curso de Pós-graduação em Veterinária, Universidade Federal de Pelotas, RS.

PEREIRA, D.B. et al. Estudos complementares da infecção por Mannheimia granulomatis (lechiguana) em bovinos. Pesquisa Veterinária Brasileira, v.20, n.3, p.91-96, setembro, 2000. Disponível em: <http://www.scielo.br/ s c i e lo.ph p s c ript $=$ s ci_art text \& pi d = S $0100-$ $736 \mathrm{X} 2000000300001 \& \operatorname{lng}=\mathrm{en} \& \mathrm{nrm}=\mathrm{iso}>$. Acesso em: $17 \mathrm{jan}$. 2010. doi: 10.1590/S0100-736X2000000300001.

RIBEIRO, P.B.; DE OLIVEIRA, C.M.B. Fase parasitária da Dermatobia hominis sobre bovinos. Arquivo Brasileiro de Medicina Veterinária e Zootecnia, v.35, n.5, p.691-698. 1983.
RIET-CORREA, F. et al. Bovine focal proliferative fibrogranulomatous panniculitis (lechiguana) associated with Pasteurella granulomatis. Veterinary Pathology, v.29, p.93103, march, 1992. Disponível em: <http://vet.sagepub.com/ content/29/2/93>. Acesso em: 17 jan. 2010. doi: 10.1177 030098589202900201

ANDRADE, G.B. et al. Lechiguana (focal proliferative fibrogranulomatous panniculitis) in cattle. Veterinary Research Communications, v.24, p.557-572, 2000. Impresso, ISSN/ISBN: 01657380.

SANAVRIA, A. et al. Histopatologia da pele de bovino na infecção experimental por Dermatobia hominis. Arquivos da Universidade Federal Rural do Rio de Janeiro, v.10, n.12, p.9-23, 1987

VARASCHIN, M.S.; SILVA, A.M. Paniculite fibrogranulomatosa focal em bovino de Minas Gerais. Ciência Rural, v.28, n.1, mar., p.151-153, 1998. Disponível em: <http://www.scielo.br/ s cielo.php? s cript=s ci_arttext \& pid = S 0103 $84781998000100027 \& \operatorname{lng}=\mathrm{pt} \& \mathrm{nrm}=\mathrm{iso}>$. Acesso em: 18 jan. 2010. doi: 10.1590/S0103-84781998000100027. 